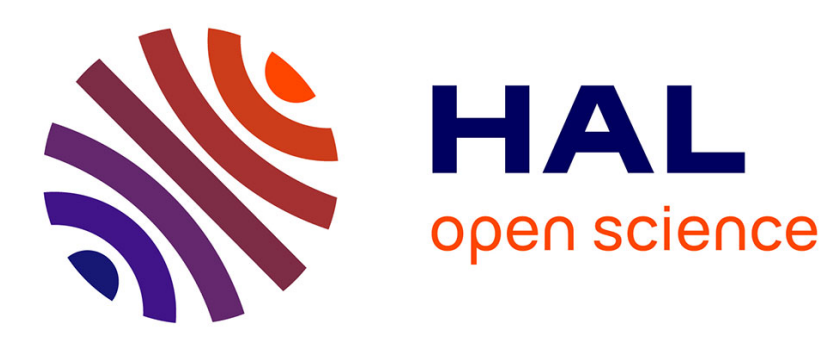

\title{
Small angle X-ray scattering and the structure of Ge-S and GeS2-Ag2S glassy systems
}

\author{
P. Armand, A. Ibanez, E. Philippot, C. Williams, D. Bittencourt
}

\section{To cite this version:}

P. Armand, A. Ibanez, E. Philippot, C. Williams, D. Bittencourt. Small angle X-ray scattering and the structure of Ge-S and GeS2-Ag2S glassy systems. Journal de Physique IV Proceedings, 1993, 03 (C8), pp.C8-389-C8-392. 10.1051/jp4:1993881 . jpa-00252312

\section{HAL Id: jpa-00252312 https://hal.science/jpa-00252312}

Submitted on 1 Jan 1993

HAL is a multi-disciplinary open access archive for the deposit and dissemination of scientific research documents, whether they are published or not. The documents may come from teaching and research institutions in France or abroad, or from public or private research centers.
L'archive ouverte pluridisciplinaire HAL, est destinée au dépôt et à la diffusion de documents scientifiques de niveau recherche, publiés ou non, émanant des établissements d'enseignement et de recherche français ou étrangers, des laboratoires publics ou privés. 


\title{
Small angle $\mathrm{X}$-ray scattering and the structure of $\mathrm{Ge}-\mathrm{S}$ and $\mathrm{GeS}_{2}-\mathrm{Ag}_{2} \mathrm{~S}$ glassy systems
}

\author{
P. ARMAND, A. IBANEZ, E. PHILIPPOT, C. WILLIAMS* and D. BITTENCOURT ${ }^{* *}$ \\ Lab. Physicochimie des Matériaux, UM II, 34095 Montpellier cedex 5, France \\ * LURE, Bât. 209D, Université de Paris-Sud, 91405 Orsay, France \\ ** Instituto de Física, Universidade de São Paulo, C.P. 20516, CEP 01498-970, São Paulo, Brazil
}

\begin{abstract}
The homogeneity of binary $\operatorname{GeS}_{\mathrm{x}}(1.5 \leq \mathrm{x} \leq 5)$ and ternary (1-y) $\mathrm{GeS}_{2}+\mathrm{yAg} 2 \mathrm{~S}$ $(0.05 \leq y \leq 0.5)$ glasses has been characterized from SAXS experiments. The scattering intensity of GeSx binary glasses is weak and present a monotonous decay only fitted by using a Debye-Büeche model. These results seem to indicate that $\mathrm{GeS}_{\mathbf{X}}$ glassy network have only weak fluctuations of electron density, correlated in a few hundred of Angstroms in agreement with a rather continuous glassy network picture, without definite clusters in the structure. On the other hand, the ternary glasses show an important evolution versus composition. For small amount of Ag2S, the glassy network modifier is not well "dilute" in the glass former $\mathrm{GeS}_{2}$. This induces the formation of $\mathrm{Ag}_{2} \mathrm{~S}$ clusters which are characterized by a correlation peak and a Porod region. When the $\mathrm{Ag}_{2} \mathrm{~S}$ proportion increases, the "dilution" of the glass modifier is improved due to the typical depolymerization of the glass matrix. This lead, for $\mathrm{Ag}_{2} \mathrm{~S}$ enriched composition $(y>0.3)$ to a more homogeneous distribution of silver in the glass which is characterized also by a Debye-Büeche model for the scattered intensity.
\end{abstract}

\section{Introduction.}

Germanium chalcogenide glasses have been intensively investigated for the last two decades. In fact, they are promising materials for memory or switching devices $[1,2]$. On the other hand, thin films doped with silver are interesting for submicrometer lithography [3]. Furthermore, bulk ternary glasses of Ag-Ge-X (X = S,Se) systems are good solid electrolytes. Their $\mathrm{Ag}^{+}$ionic conductivity is significantly increased by the addition of doping salts which are generally silver halogenides [4]. All these physical properties have been very well characterized, nevertheless, the basic mechanism of the radiation-enhanced metal dissolution as well as the ionic transport process phenomenon are not well known from a microscopic point of view. This is mainly due certainly to a poor knowledge of the structure of these amorphous materials. For these reasons, several structural studies have been made using IR, Raman, photoemission, Mössbauer and absorption spectroscopies for example.

In this field we have undertaken a structural characterization of Ge-X,GeX ${ }_{2}-\mathrm{Ag}_{2} \mathrm{X}$ ( $\left.\mathrm{X}=\mathrm{S}, \mathrm{Se}\right)$ glassy systems by X-ray Absorption Spectroscopy (XAS). Thus, the short range order (SRO) existing in these glasses around germanium, silver or chalcogen atoms has been defined by EXAFS (Extended X-ray Absorption Fine Structures) and XANES (X-ray Absorption Near Edge Structures) experiments $[5,8]$. This structural approach has been followed by Anomalous Wide Angle X-ray Scattering (AWAXS) characterization [9] to improve our knowledge of the intermediate range order (IRO) of these glasses until 6-8 $\AA$.

Nevertheless, all these first structural results must be completed by Small Angle X-ray Scattering (SAXS) experiments in order to check the homogeneity of these glassy phases leading thus to a current knowledge of their amorphous structures in a range of 0 to $1000 \AA$

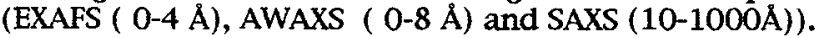


In this paper we present our main SAXS results obtained for GeSx $(1.5 \leq \mathrm{x} \leq 5)$ and (1-y) GeS2 $+\mathrm{yAg}_{2} \mathrm{~S}(0.05 \leq \mathrm{y} \leq 0.5)$ glassy compositions.

\section{Experimental.}

The glassy samples were prepared by alloying the pure elements in quartz tubes, sealed under high vacuum $\left(10^{-5}\right.$ Torr). The melts were equilibrated at $900 \mathrm{C}-1000 \mathrm{C}$ during a week with periodic shaking and then quenched in water. In order to obtain thin samples (thickness approx. $50 \mu \mathrm{m}$ ) for SAXS experiments, theses glasses were melt again and quenched using the twin-roller technique under glove-box containing argon.

The glassy state of these materials were characterized by X-ray diffraction and their atomic composition were check by X-ray fluorescence measurements.

The SAXS spectra were recorded on the D-22 line at LURE (ORSAY) using synchrotron radiation from a beam line of DCI storage ring operating at $1.85 \mathrm{GeV}$ and average current of $250 \mathrm{~mA}$. After monochromatization using double Ge 111 parallel crystals, the energy of the Xray beam was tuned on $8500 \mathrm{eV}$. The sample - detector distance, adjusted by modular vacuum tubes, was either $1990 \mathrm{~mm}$ or $1035 \mathrm{~mm}$. The D-22 line is characterized by high energy resolution and moderate flux as described elsewhere [10] .

All spectra were corrected for the primary intensity of the beam, sample to detector distance and solid angle, counting time, dimensions of the slits, detectors dead time, using a software written by 0 . Lyon. The spectra were also corrected for blank scattering, sample absorption and thickness. All spectra are in relative but consistent units.

\section{Results and discussion.}

\section{a) GeSx Binary Glasses}

All the SAXS spectra recorded for $\operatorname{GeS}_{\mathrm{X}}(1.5 \leq \mathrm{x} \leq 5)$ glasses are very similar, figure 1 . They present a monotonous decay of the scattering intensity $\mathrm{I}(\mathrm{q}),(\mathrm{q}=4 \pi \sin \theta / \alpha$ ), and have been fitted using a Debye Büeche model $[11,12], I(q)=K 1^{3} /\left(1+1^{2} q^{2}\right)^{2}$ were 1 is a correlation length corresponding to a distance of "correlated "disorder .

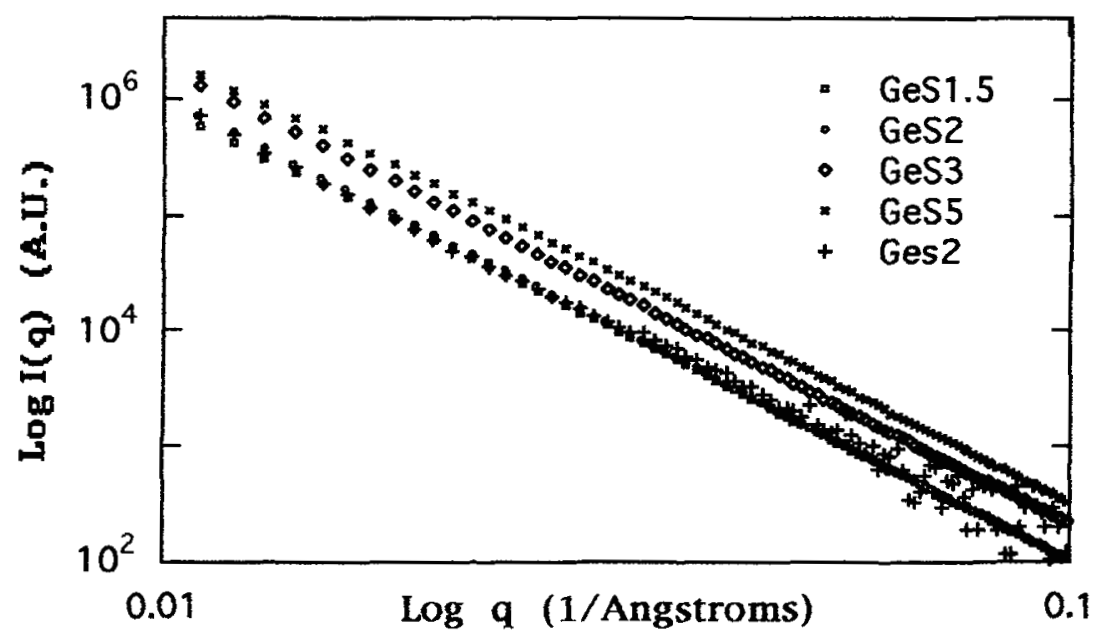

Fig.1. Fitted intensities for GeSx binary glasses according Debye-Büeche model. Correlations lengths are $267 \AA$ for $\mathrm{GeS}_{1.5} ; 741 \AA$ for $\mathrm{GeS}_{2} ; 329 \AA$ for $\mathrm{GeS}_{3}$ and $207 \AA$ for $\mathrm{GeS}_{5}$. As the experimental scattered intensities superimposes for high $\mathrm{q}$, only $\mathrm{GeS}_{2}$ is showed $(+)$. 
This low scattering intensity without peak correlation, Guinier or Porod region seems to be only due to weak filuctuations of electron density correlated in a range from 200 to $700 \AA$. These results, showing clearly the absence of definite clusters in these glassy structures, are in agreement with our structural results obtained at short and intermediate range orders by EXAFS and AWAXS. Indeed, these previous works seem indicate, for these $\mathrm{GeS}_{\mathrm{X}}$ binary glasses, continuous glassy network based upon the crystalline structure having the nearest atomic composition ("distorted crystalline network" model) [8].

\section{b) $\left(1-\right.$ y) $\mathrm{GeS}_{2}+$ y $\mathrm{Ag}_{2} \mathrm{~S}$ Ternary Glasses}

The SAXS spectra of $(1-y) \mathrm{GeS}_{2}+\mathrm{y} \mathrm{Ag}_{2} \mathrm{~S}$ present an important evolution versus composition (figure 2).

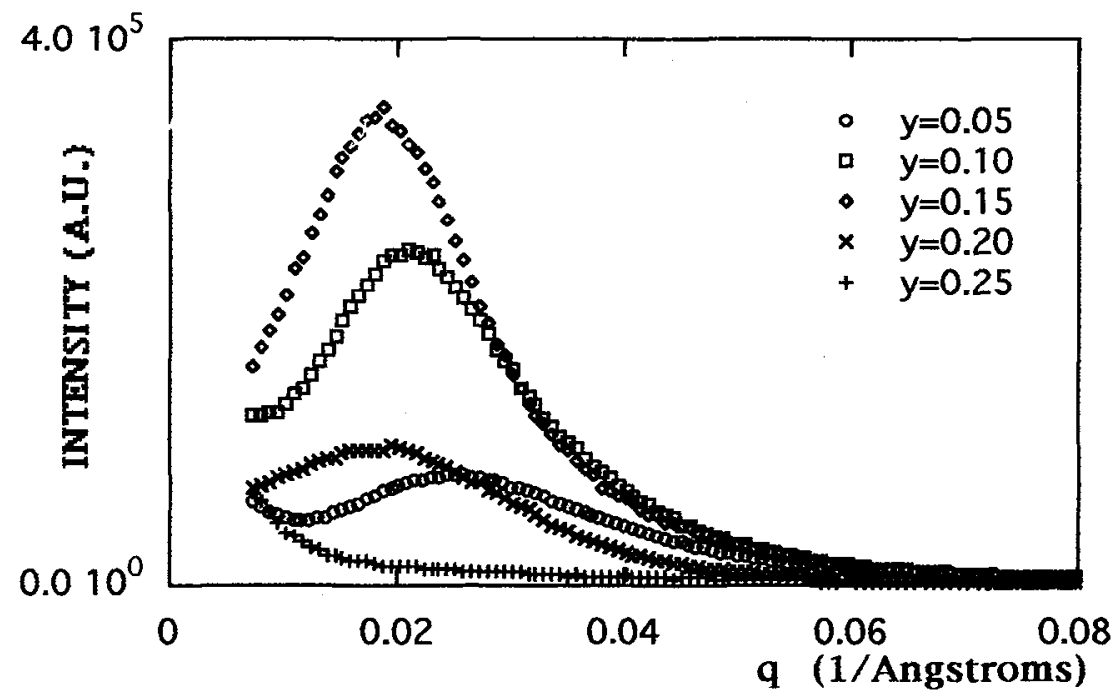

Fig.2. Scattered intensities for $(1-\mathrm{y}) \mathrm{GeS}_{2}+\mathrm{y} \mathrm{Ag}_{2} \mathrm{~S}$ ternary glasses

For glasses with low $\mathrm{Ag}_{2} \mathrm{~S}$ concentration $(0.05 \leq \mathrm{y} \leq 0.2)$, the scattering intensity $\mathrm{I}(\mathrm{q})$ show a peak and its scattering tail obeys Porod's law, $I(q)=f\left(q^{-4}\right)[13]$.

When the $\mathrm{Ag}_{2} \mathrm{~S}$ proportion increases, the peak broadness out to become a shoulder for $\mathrm{y}=0.25$ glassy composition and disappears for $\mathrm{Ag}_{2} \mathrm{~S}$ enriched glasses $(\mathrm{y} \geq 0.3)$ (Table 1).

Table 1 . Some parameters from the scattering curves of $(1-y) \mathrm{GeS}_{2}+\mathrm{y}_{2} \mathrm{~S}$ ternary glasses. $R p$ is the Porod radius, qmax is the peak position, $n$ is the power dependence of $I(q)$ for the scattering tail.

$\begin{array}{cllc}\mathbf{y} & \begin{array}{c}\mathbf{R p} \\ (\AA)\end{array} & \begin{array}{l}\mathbf{q m a x} \\ (1 / \AA)\end{array} & \mathbf{n} \\ 0.05 & 23 & 0.0250 & -3.90 \\ 0.10 & 34 & 0.0215 & -4.01 \\ 0.15 & 34 & 0.0186 & -4.12 \\ 0.20 & 26 & 0.0170 & -3.61 \\ 0.25 & 20 & \text { bump } & -2.72\end{array}$


On the other hand, the Porod region is made worse $(n=-2.7 \bar{Z}$ for $y=0.25$ and $n=-2.50$ for $y=$ 0.3 ), while the corresponding Porod radius is decreased significantly ( $R p=20 \AA$ for $y=0.25$ and $\mathrm{Rp}=17 \AA$ for $\mathrm{y}=0.3$ ). For $\mathrm{y} \geq 0.3$ compositions, the scattering intensity, $\mathrm{I}(\mathrm{q})$, presents weaker values and a monotonous decay alike the binary glasses, which can be also simulated by a Debye Büeche model with correlations lengths of $290 \AA(y=0.4)$ and $183 \AA(y=0.5)$.

These results seem to demonstrate that the glassy network modifier, for small amount of $\mathrm{Ag}_{2} \mathrm{~S}$, is not well "dilute" in the glassy matrix. This induces the formation of $\mathrm{Ag}_{2} \mathrm{~S}$ clusters with sharp boundary for $0.05 \leq y \leq 0.2$ compositions. The mean size of these clusters is about $30 \AA$. When the $\mathrm{Ag}_{2} \mathrm{~S}$ percentage increases, the $\mathrm{Ag}_{2} \mathrm{~S}$ aggregates become smaller $(17 \AA$ for $\mathrm{y}=0.3)$ and there is no sharp boundary ( $\mathrm{I}(\mathrm{q})$ deviates from Porod's law). On the other hand, the $\mathrm{Ag}_{2} \mathrm{~S}$ cluster distribution in the glass is loosing order as indicated by the broadening of the peak. This seems to demonstrate that the "dilution" of $\mathrm{Ag}_{2} \mathrm{~S}$ is improved, leading to a more homogeneous repartition of silver in the glass for $\mathrm{Ag}_{2} \mathrm{~S}$ enriched samples $(\mathrm{y} \geq 0.3)$.

These structural conclusions are well consistent with the EXAFS results obtained at the Ag Kedge [7].

\section{Conclusions}

This SAXS study have allowed us to complete and to confirm our structural characterization of germanium chalcogenide glasses previously made at the short and intermediate range orders by EXAFS and AWAXS.

The main point coming out of our investigation are as follows:

(i) All the GeS $\mathrm{X}$ glasses seem to present a continuous glassy network without definite cluster. The low scattering intensities registered in the SAXS spectra would only due to weak fluctuations of electron density in a length scale of 200-700 A.

(ii) For weak $\mathrm{Ag}_{2} \mathrm{~S}$ proportions, the structure of (1-y) $\mathrm{GeS}_{2}+\mathrm{y} \mathrm{Ag}_{2} \mathrm{~S}$ glasses $(0.05 \leq \mathrm{y} \leq 0.2)$ is demixed and certainly constituted by two types of clusters: "GeS 2 " clusters based on the layered $\alpha \mathrm{GeS}_{2}$ crystalline network and $\mathrm{Ag}_{2} \mathrm{~S}$ aggregates based on the structure of $\beta \mathrm{Ag}_{2} \mathrm{~S}$.

(iii) When the proportion of the $\mathrm{Ag}_{2} \mathrm{~S}$ glassy network modifier increases, its "dilution" is improved due to the breaking of Ge-S-Ge linkages and thus leading to smaller $\mathrm{Ag}_{2} \mathrm{~S}$ clusters ( $\mathrm{Rp}$ approx. $20 \AA$ ). Then, for high $\mathrm{Ag}_{2} \mathrm{~S}$ contents $(\mathrm{y}>0.3)$ the distribution of silver atoms is much more homogeneous in the glassy network .

\section{References}

[1] B.T. Kolomiets, Phys. Status Solidi, 7, 359 (1964).

[2] S.R. Ovskinsky, Phys. Rev. Lett., 21, 1450 (1968).

[3] D.A. Doane and A. Heller, Eds. "Proc. Symp. Inorganic.Resist Systems", Electrochemical Soc. (1982).

[4] E. Robinel, B. Carette and M. Ribes, J. Non-Cryst. Solids, 57, 49 (1983).

[5] A. Ibanez, E. Philippot, S. Benazeth and H. Dexpert, J. Non-Cryst. Solids, 127, 25 (1991).

[6] P. Armand, A. Ibanez, H. Dexpert and E. Philippot., J. Non-Cryst. Solids, 139,137 (1992).

[7] A. Ibanez, P. Armand, E. Philippot and H. Dexpert, Solid State Ionics, 59, 157 (1993).

[8] P. Armand, A. Ibanez and E. Philippot, will be published in J. Solid State Chem., 103 (1993).

[9] P. Armand, A. Ibanez, E. Philippot, Q MA and D. Raoux, J. Non-Cryst. Solids, 150, 371 (1992).

[10] J.M. Dubuissom ; J.M. Dauvergne ; C. Depautex ; P. Vachete ; C. E. Williams, Nucl. Instr. Meth., A246,630 (1986).

[11] P. Debye; A.M. Büeche, J. App. Phys.,20,518 (1949).

[12] P. Levitz; D.Tchoubar; J.Phys. I France,2,771 (1992)

[13] G. Porod, "Small Angle X-ray Scattering",ed. O. Glater and O. Kratky,(1982) 